\title{
Enhancement of Power Quality and Speed Regulation of a BLDC Motor Drive using Water Cycle Algorithm
}

\author{
Shreekara S Hegde \\ M. tech PE, Dept. of EEE \\ BMS College of Engineering,Bangalore
}

\author{
A. N. Nagashree \\ Associate professor,Department of EEE \\ BMS College of Engineering,Bangalore
}

\begin{abstract}
Permanent magnet Brushless DC motors are used in several applications because of its advantages such as high reliability, high power output, constant torque, low maintenance cost, good heat dissipation and better efficiency. Also, rapidly decreasing cost of permanent magnets is an added advantage. Hence, BLDC motors are suitable for many variable-speed drive applications. Various DC-DC converters are used for driving the BLDC motor and Interleaved Boost converter is one of them. BLDC motor drive is fed through a diode bridge rectifier which lowers the power factor. Hence, power factor correction converters are necessary in such applications. In the present work, to improve the power quality of the $\mathrm{AC}$ mains and hence the power factor, Interleaved boost converter controlled by PI controller is used. The gains of the PI controller are decided by Water cycle algorithm (WCA) using Integral Time Absolute Error (ITAE) criterion. Speed control of the BLDC motor is done by controlling the output voltage of the converter which acts as a DC link voltage to the Three Phase Voltage Source Inverter (VSI). MATLAB SIMULINK software is used for the design and performance analysis of the BLDC.
\end{abstract}

Keywords:- DC link voltage, Matlab-Simulink, Permanent magnet Brushless DC motor, power factor, power factor correction, converter, Three Phase Voltage Source Inverter.

\section{INTRODUCTION}

Permanent magnet Brushless Direct Current (PMBLDC) motors are used in wide variety of applications due to several advantages [1]. These motors have high power density, high efficiency, low Electromagnetic Interference (EMI) problem, ease of control, low maintenance, high reliability, lower weight, high flux density per unit volume and noiseless operation [1,2,3]. This motor is one of the types of synchronous motors. [3]. It has stator windings i.e. the armature and a permanent magnet as the rotor [3]. The armature consists of stacked laminations made up of steel [4,5]. The armature windings are placed in slots that are wound around poles of the armature $[4,5]$. The permanent magnets acting as rotor can change from 2 to 8 pairs of poles with alternate north and south poles [4]. BLDC motor makes use of an electronic commutator for rotor position detection [5]. Hence, three Hall sensors are placed on stator with each having phase shift of $120^{\circ}$ [5]. Current is supplied to motor coils by the sensing of permanent magnet or electromagnet's magnetic field [6]. Based on the current, the magnets rotate at the correct orientation [6]. Conventional machines like DC and synchronous machines have wear and tear problems due the presence of commutator brush assembly [6,7,8]. In Brushless direct current motor, wear and tear problem does not exist since an electronic commutator is used for rotor position detection instead of a mechanical commutator [7]. Hall sensors, resolvers and shaft encoders are usually used to find the rotor angle position [7,8].

Use of a BLDC motor for Air-conditioning system can result in advantages like lesser electrical and mechanical stress, longer life, higher reliability and lower running cost when compared to the conventional machines [9]. Also, during speed control mode, the load of the Airconditioning system exerts a fixed torque [10].

The drive used for BLDC motor is fed through AC mains supply [11]. Since the mains voltage has to be converted into a less pulsating DC voltage, a capacitor is usually used at the output of the bridge rectifier [11]. Since the charging of the capacitor is uncontrollable, it results in the degradation of the power quality and increase in Total Harmonic Distortion (THD) of the input current [12]. The input current rises up to a very high value and causes damage to other components as well [12]. The input current from the mains is expected to be such that it has to be acceptable according to the International PQ standards IEC 61000-3-2 [12,13,14]. Hence, there is a need for improvement of the quality of power [15]. Several topologies of switched mode power converters are used to enhance the quality of power $[15,16,17]$. The source of the Power electronic switch is not connected to ground for a buck converter [17]. This results in a difficulty for designing the gate circuit [17]. The same problem is faced by Buck-boost, Cuk topologies due to reversal of output voltage polarity [17]. Zeta converters also face this problem due switch in series to the supply [17]. An Interleaved boost converter proves to be a suitable solution for the above mentioned issues.

In the present work, an interleaved boost converter is used for the proposed BLDC motor drive which is operated in Continuous Conduction Mode (CCM). Lesser inductor current ripple, lower output voltage ripple, lesser size of 
components, continuous input current etc. are few advantages of interleaved converter [18]. Hence it proves to be a promising drive for BLDC motor. Additionally, by regulating the DC link voltage of inverter, the motor speed can be regulated. PI controllers are robust, simple, less expensive and used in various applications [19,20]. The manual tuning of the controller is a tedious procedure and also time consuming [20]. Hence there is a need of an optimization algorithm which can easily tune PI controller parameters. A metaheuristic optimization technique named Water Cycle Algorithm (WCA) has application in wide range of optimization [21]. Use of WCA results in substantial improvement of the PI controller parameters [20]. Minimizing Integral Time Absolute Error (ITAE) is considered to be as a good performance index in designing PI controllers [22]. Hence, in present work, the design and analysis of the BLDC drive is done by ITAE index using the Water cycle algorithm for air conditioner compressor application.

\section{PROPOSED SPEED CONTROLLED PFC DRIVE}

Fig. 1 shows the proposed speed controlled Power factor enhancer drive. AC mains voltage $220 \mathrm{~V}$ is stepped down to $110 \mathrm{~V}$ using a stepdown transformer. The stepped down voltage is converted to pulsating DC voltage by utilizing a bridge rectifier. This acts as the input to the interleaved boost converter. The converter boosts the output voltage to $310 \mathrm{~V}$. This acts as the DC link voltage to the inverter. The Inverter powers the BLDC motor. Hall sensors present in the stator of the motor detect the rotor position. Depending on its position, respective switches of inverter will be ON. This leads to the respective stator windings to be energized.

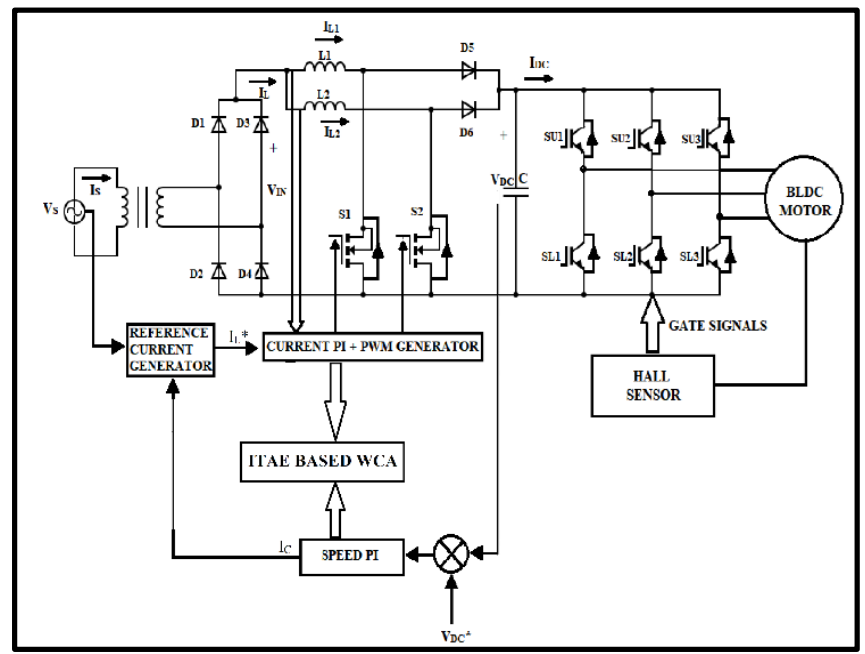

Fig 1:- Block diagram depicting the complete PFC system

Interleaved Boost Converter and Inverter have MOSFET and IGBT as power electronic switches. To improve the quality of power, the controller uses current multiplier technique [24]. The overall controller consists of a speed loop which is slow acting and a current loop which is fast acting. The capacitor voltage of the converter is equivalent to motor speed which is sensed and fed back to a comparator with $\mathrm{DC}$ voltage reference $\left(\mathrm{V}_{\mathrm{DC}}{ }^{*}\right)$. The error is given to the Outer speed PI controller. The resulting current control signal is multiplied by an absolute unity amplitude sine wave to obtain the reference for Inductor current $\left(\mathrm{I}_{\mathrm{L}}{ }^{*}\right)$. The obtained current signal is compared with inductor currents $\mathrm{I}_{\mathrm{L} 1}$ and $\mathrm{I}_{\mathrm{L} 2}$ of the converter. The error is given to the fast acting inner current PI controller. Thus modulating signals $m_{1}$ and $m_{2}$ are obtained. The obtained signals are compared with saw tooth carrier of unity amplitude. This saw tooth signal has a constant frequency with a phase delay of $0^{\circ}$ and $180^{\circ}$ respectively. The comparison gives PWM signals for the converter switches. With the change in reference $\mathrm{V}_{\mathrm{DC}}{ }^{*}$, the output voltage of converter tracks it. Since this voltage is equivalent to motor speed, change in this reference leads to different voltage levels and hence different speed levels of the motor. This results in the speed regulation of the motor.

\section{DESIGN OF THE CONVERTER}

The Converter presented in this work utilized in enhancing the power quality has same equations for calculation of parameters as it is for the boost converter.

The relation between stepped down voltage $\mathrm{V}_{\mathrm{ST}}$ and the converter input voltage is given by:

$\mathrm{V}_{\mathrm{IN}}=2 \sqrt{2} \mathrm{~V}_{\mathrm{ST}} / \pi[24]$

The converter output voltage is calculated by:

$$
\mathrm{V}_{\mathrm{O}}=\mathrm{V}_{\mathrm{DC}}=\mathrm{V}_{\mathrm{IN}} /(1-\mathrm{D})[24]
$$

Where, D is the ratio of ON time of switches to total time of the switches. $\mathrm{V}_{\text {IN }}$ is the bridge rectifier output. This is the supply to the converter.

Similarly, the relation between Converter input and output current is given by:

$\mathrm{I}_{\mathrm{O}} / \mathrm{I}_{\mathrm{IN}}=(1-\mathrm{D})$

Where, $\mathrm{I}_{\mathrm{IN}}$ is the converter input current which is equal to the total inductor current. $\mathrm{I}_{O}$ is the converter output current supplied to the inverter.

$$
\begin{aligned}
& \text { Equation for boost inductors is given by- } \\
& \qquad \begin{array}{l}
\mathrm{L}_{1}=\mathrm{DV}_{\mathrm{IN}} /\left\{\mathrm{f}_{\mathrm{S}}\left(\Delta \mathrm{I}_{\mathrm{L} 1}\right)\right\} \\
\mathrm{L}_{2}=\mathrm{DV} \mathrm{V}_{\mathrm{IN}} /\left\{\mathrm{f}_{\mathrm{S}}\left(\Delta \mathrm{I}_{\mathrm{L} 2}\right)\right\}
\end{array}
\end{aligned}
$$

Where, $\Delta \mathrm{I}_{\mathrm{L} 1}, \Delta \mathrm{I}_{\mathrm{L} 2}$ are the ripples in Inductor currents $\Delta \mathrm{I}_{\mathrm{L} 1}$ and $\Delta \mathrm{I}_{\mathrm{L} 2}$. $\mathrm{f}_{\mathrm{S}}$ is MOSFET switching frequency. The current through each inductor is half of the total inductor current since the inductor current is divided in two branches. The equation for output capacitor is given by:

$$
\mathrm{C}=\mathrm{DI}_{\mathrm{DC}} / \mathrm{f}_{\mathrm{S}}\left(\Delta \mathrm{V}_{\mathrm{O}}\right)
$$

where, $\Delta \mathrm{V}_{\mathrm{O}}$ is the ripple of output capacitor. $\mathrm{I}_{\mathrm{DC}}$ is the input current through the Inverter. 
The converter is designed so that the converter output voltage $\mathrm{V}_{\mathrm{O}}=\mathrm{V}_{\mathrm{DC}}=310 \mathrm{~V}$. Switching frequency of individual switch is selected as $10 \mathrm{kHz}$. Input inductor value and capacitor value obtained after calculation are $27.18 \mathrm{mH}$ and $0.3738 \mathrm{mF}$ respectively.

\section{BLDC MOTOR DRIVE}

The proposed drive comprises of a i) Hall sensor ii) Three Phase Voltage Source Inverter iii) BLDC motor.

\section{$>$ Hall sensor}

Three hall sensors fixed to stator are used in detecting the rotor angle position [23].

Table 1 shows the switching sequence of Inverter corresponding to Hall sensor output [24].

\begin{tabular}{|c|c|c|c|c|c|c|c|c|}
\hline \multicolumn{7}{|c|}{$\begin{array}{c}\text { Output of the } \\
\text { sensor }\end{array}$} & \multicolumn{7}{|c|}{ Sequence of switching } \\
\hline $\mathrm{H}_{\mathrm{a}}$ & $\mathrm{H}_{\mathrm{b}}$ & $\mathrm{H}_{\mathrm{c}}$ & $\mathrm{S}_{\mathrm{U} 1}$ & $\mathrm{~S}_{\mathrm{L} 1}$ & $\mathrm{~S}_{\mathrm{U} 2}$ & $\mathrm{~S}_{\mathrm{L} 2}$ & $\mathrm{~S}_{\mathrm{U} 3}$ & $\mathrm{~S}_{\mathrm{L} 3}$ \\
\hline 0 & 0 & 0 & 0 & 0 & 0 & 0 & 0 & 0 \\
\hline 0 & 0 & 1 & 0 & 0 & 0 & 1 & 1 & 0 \\
\hline 0 & 1 & 0 & 0 & 1 & 1 & 0 & 0 & 0 \\
\hline 0 & 1 & 1 & 0 & 1 & 0 & 0 & 1 & 0 \\
\hline 1 & 0 & 0 & 1 & 0 & 0 & 0 & 0 & 1 \\
\hline 1 & 0 & 1 & 1 & 0 & 0 & 1 & 0 & 0 \\
\hline 1 & 1 & 0 & 0 & 0 & 1 & 0 & 0 & 1 \\
\hline
\end{tabular}

Table 1:- Switching sequence of Inverter corresponding to Hall sensor [24]

Based on the information on rotor angle, Corresponding signals are given from hall sensors and respective switches of inverter are made ON and OFF [23]. This ensures that corresponding stator windings are excited [23].

\section{Three Phase Voltage Source Inverter-}

Fig. 2 shows the Voltage source Inverter to which the armature windings of the BLDC motor are connected. It is operated in 120 degree conduction mode to excite the motor.

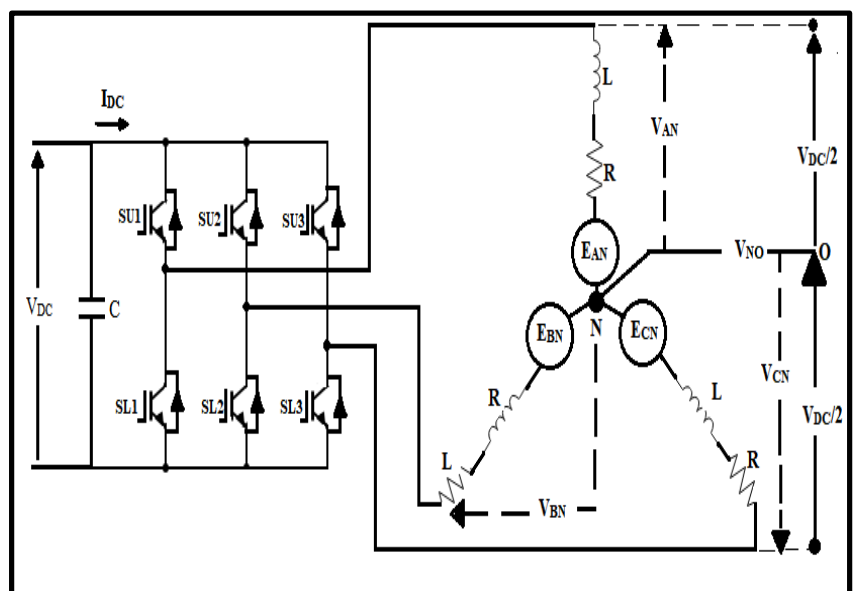

Fig 2:- Three Phase Voltage source Inverter [24]
The phase voltages of $\mathrm{a}, \mathrm{b}$ and $\mathrm{c}$ phases are given by:

$$
\begin{aligned}
& V_{\text {PHASE }}=V_{D C} / 2 \text { for } S_{U}=1 \\
& V_{\text {PHASE }}=-V_{D C} / 2 \text { for } S_{L}=1 \\
& V_{\text {PHASE }}=0 \text { for } S_{L}=0 \text { and } S_{U}=0
\end{aligned}
$$

Where, $\mathrm{V}_{\mathrm{DC}}$ is the DC link voltage [13]. $\mathrm{S}_{\mathrm{U}}$ represents the Upper leg switches. $S_{L}$ represents the Lower leg switches of the Inverter. The values $1 \& 0$ depict the states "ON" and "OFF" of the Inverter IGBT switches.

\section{BLDC Motor}

The Brushless Direct Current motor modelling is done using differential equations [24]:

$\mathrm{V}_{\mathrm{X}}=\mathrm{I}_{\mathrm{X}} \mathrm{R}_{\mathrm{X}}+\mathrm{dI} \mathrm{I}_{\mathrm{X}} / \mathrm{dt}\left(\mathrm{L}_{\mathrm{X}}+\mathrm{M}\right)+\mathrm{E}_{\mathrm{X}}$

Where, " $\mathrm{x}$ " implies $\mathrm{a}, \mathrm{b}$ and $\mathrm{c}$ phases of the inverter.

$\mathrm{V}_{\mathrm{X}}$ represents the inverter output voltage in volts. $\mathrm{I}_{\mathrm{X}}$ represents the stator winding currents in amperes.

$\mathrm{R}_{\mathrm{X}}$ represents the resistance/phase in ohms.

$E_{X}$ represents the EMF generated by stator windings in volts.

$\left(\mathrm{L}_{\mathrm{X}}+\mathrm{M}\right)$ represents the self-inductance and mutual inductance in Henry.

$$
\mathrm{T}_{\mathrm{E}}=\mathrm{T}_{\mathrm{L}}+\mathrm{J} \mathrm{d} \omega / \mathrm{dt}+\mathrm{B} \omega[5,24]
$$

Where, $\mathrm{T}_{\mathrm{E}}$ is the torque produced by the motor in $\mathrm{Nm}$. $\mathrm{T}_{\mathrm{L}}$ represents compressor load torque in $\mathrm{Nm}[5,24]$. $\mathrm{J}$ depicts moment of Intertia in $\mathrm{kgm}^{2}[5,24]$. $B$ represents the viscous damping in Nms/(rad) [5,24]. $\omega$ is the speed of the motor in $\mathrm{rad} / \mathrm{s}[5,24]$.

$\omega=\mathrm{d} \theta / \mathrm{dt}$

$\omega_{\mathrm{r}}=(\mathrm{P} / 2) * \omega$

Where, $\theta$ is the angle of rotor position in degrees.

The emf produced at stator can be implicated by a function of the rotor angle $(\theta)[10,24]$ as:

$E_{X}=K_{B} f_{X}(\theta) \omega_{r}[5]$

Where, $K_{B}$ represents the constant of stator emf in volts/(rad/s) [10,24]. $f_{X}(\theta)$ implicates the rotor angle function. It has a unity value of upper and lower bound i.e. \pm 1 . 
Table 2 shows the function of rotor position at different rotor angles [25]

\begin{tabular}{|c|c|c|c|}
\hline$\theta$ (degrees) & $\mathrm{f}_{\mathrm{A}}(\theta)$ & $\mathrm{f}_{\mathrm{B}}(\theta)$ & $\mathrm{f}_{\mathrm{C}}(\theta)$ \\
\hline $0^{\circ}-60^{\circ}$ & $(6 \theta / \pi)-1$ & 1 & -1 \\
\hline $60^{\circ}-120^{\circ}$ & 1 & $3-(6 \theta / \pi)$ & -1 \\
\hline $120^{\circ}-180^{\circ}$ & 1 & -1 & $(6 \theta / \pi)-5$ \\
\hline $180^{\circ}-240^{\circ}$ & $7-(6 \theta / \pi)$ & -1 & 1 \\
\hline $240^{\circ}-300^{\circ}$ & -1 & $(6 \theta / \pi)-9$ & 1 \\
\hline $300^{\circ}-360^{\circ}$ & -1 & 1 & $11-(6 \theta / \pi)$ \\
\hline
\end{tabular}

Table 2:- Back EMF modelled as a function of Rotor angle [25]

The motor torque is given by the equation shown by:

$T_{E}=K_{B}\left[f_{A}(\theta) I_{A}+f_{B}(\theta) I_{B}+f_{C}(\theta) I_{C}\right][5,24]$

Equations (10)-(15) depict the overall dynamic BLDC motor model.

Table 3 displays the specifications of the motor

\begin{tabular}{|c|c|}
\hline $\mathrm{P}_{\text {rated }}$ & $375 \mathrm{~W}$ \\
\hline $\mathrm{N}_{\text {rated }}$ & $3000 \mathrm{rpm}$ \\
\hline $\mathrm{V}_{\text {rated }}$ & $310 \mathrm{~V}$ \\
\hline $\mathrm{T}_{\text {rated }}$ & $1.2 \mathrm{Nm}$ \\
\hline $\mathrm{K}_{\mathrm{T}}$ & $0.744 \mathrm{Nm} / \mathrm{A}$ \\
\hline Pole pairs & 2 \\
\hline $\mathrm{R}_{\mathrm{s}}$ & $14.56 \Omega$ \\
\hline $\mathrm{L}_{\mathrm{s}}$ & $25.71 \mathrm{mH}$ \\
\hline $\mathrm{J}$ & $0.03 \mathrm{kgm}^{2}$ \\
\hline
\end{tabular}

Table 3:- BLDC motor specifications [17]

\section{CONTROL SYSTEM OF PROPOSED DRIVE FOR POWER FACTOR ENHANCEMENT AND SPEED CONTROL}

The control system comprises of PI controllers acting as speed controller and current controllers. The gains of the controllers are tuned by the Water Cycle algorithm using ITAE index.

It consists of a) Controller Block b) Integral Time Absolute Error (ITEA) block

\section{Controller Block}

The speed controller consists of the converter output voltage $\mathrm{V}_{\mathrm{DC}}$ fed back and given to comparator with $\mathrm{DC}$ voltage reference $\mathrm{V}_{\mathrm{DC}} *$. The voltage error is given by:

$\mathrm{V}_{\mathrm{E}}(\mathrm{n})=\mathrm{V}_{\mathrm{DC}} *(\mathrm{n})-\mathrm{V}_{\mathrm{DC}}(\mathrm{n})[24]$

The error is fed to a PI controller resulting in a current control signal $\mathrm{I}_{\mathrm{C}}$.

$I_{C}(n)=I_{C}(n-1)+K_{P}\left\{V_{E}(n)-V_{E}(n-1)\right\}+K_{I} V_{E}(n)[24]$

Where $K_{P}$ is the proportional gain.

$\mathrm{K}_{\mathrm{I}}$ is the integral gain.
This signal when multiplied with an absolute unity value sine wave gives the reference for inductor current $\mathrm{I}_{\mathrm{L}} *$. current.

This reference is compared with individual inductor

$\left.\mathrm{I}_{\mathrm{E} 1}(\mathrm{n})=\mathrm{I}_{\mathrm{L}} * \mathrm{n}\right)-\mathrm{I}_{\mathrm{L} 1}(\mathrm{n})$

$\mathrm{I}_{\mathrm{E} 2}(\mathrm{n})=\mathrm{I}_{\mathrm{L}} *(\mathrm{n})-\mathrm{I}_{\mathrm{L} 2}(\mathrm{n})$

The current errors obtained are given to respective PI controllers to obtain the modulating signals $\mathrm{m}_{1}$ and $\mathrm{m}_{2}$.

$\mathrm{m}_{1}(\mathrm{n})=\mathrm{m}_{1}(\mathrm{n}-1)+\mathrm{K}_{\mathrm{P}}\left\{\mathrm{I}_{\mathrm{E} 1}(\mathrm{n})-\mathrm{I}_{\mathrm{E} 1}(\mathrm{n}-1)\right\}+\mathrm{K}_{\mathrm{I}} \mathrm{I}_{\mathrm{E} 1}(\mathrm{n})$

$\mathrm{m}_{2}(\mathrm{n})=\mathrm{m}_{2}(\mathrm{n}-1)+\mathrm{K}_{\mathrm{P}}\left\{\mathrm{I}_{\mathrm{E} 2}(\mathrm{n})-\mathrm{I}_{\mathrm{E} 2}(\mathrm{n}-1)\right\}+\mathrm{K}_{\mathrm{I}} \mathrm{I}_{\mathrm{E} 2}(\mathrm{n})$

The signals $m_{1}$ and $m_{2}$ are compared with a saw tooth carrier wave $\mathrm{S}_{\mathrm{C}}$. This has unity amplitude and constant frequency. Hence, gating signals are generated to the two MOSFETs by the relation:

if $\mathrm{m}_{\mathrm{x}}>\mathrm{S}_{\mathrm{C}}$, then $\mathrm{S}_{\mathrm{X}}=1$ else $\mathrm{S}_{\mathrm{X}}=0$, where $\mathrm{m}_{\mathrm{x}}$ represents the respective modulating signal for switch $S_{X}$. " 1 " represents "ON" and " 0 " represents "OFF" state of the MOSFET switches.

\section{Integral Time Absolute Error (ITAE) Block}

The PI controller parameters are tuned using a metaheuristic algorithm called as Water cycle algorithm. Before using any algorithm, fitness function has to be defined. The fitness function is expected to be minimized by the algorithm which results in improvement of power quality. Hence, the ITAE performance criterion is used as a fitness function which is to be minimized. The integral Time absolute of error (ITAE) criterion can be represented by the following equation as:

$\operatorname{ITAE}=\int_{0}^{\mathrm{t}} \mathrm{e}(\mathrm{t}) \mathrm{dt}$

Compared to other criterions such as Integral of the Absolute Error (IAE) or the Integral Square Error (ISE), ITAE criterion results in lesser oscillations and overshoots [26]. Sensitivity and selectivity are the added advantages of ITAE [26].

ITAE criterion is the performance index based on time integral of error. Lesser the error, more stable is the system. Hence, in the present work, the main aim of the algorithm would be to minimize the errors given to the PI controllers and thereby minimize the fitness function value.

Hence, the fitness function to be minimized would be:

$\operatorname{ITAE}=\int_{0}^{\mathrm{t}} \mathrm{e}_{1}(\mathrm{t}) d \mathrm{t}+\int_{0}^{\mathrm{t}} \mathrm{e}_{2}(\mathrm{t}) d \mathrm{t}+\int_{0}^{\mathrm{t}} \mathrm{e}_{3}(\mathrm{t}) d \mathrm{t}$

Where $e_{1}, e_{2}$ and $e_{3}$ are the errors given to the individual PI controller respectively.

" $t$ " will be the time over which the absolute value of errors will be integrated. 


\section{WATER CYCLE ALGORITHM (WCA)}

WCA is an innovative metaheuristic algorithm inspired by nature which is developed based on water cycle $[20,21,27,28,29]$. The basic idea of this algorithm is based on the movement of either streams or rivers to the sea $[20,21,28,29]$. WCA has a wide range of applications for optimization issues using user defined fixed parameters [21].

Initially, a population of raindrops is randomly created after raining process $[21,27,28]$. The best raindrop i.e. the minimum cost function raindrop is selected as the sea [20,21,27,28,29]. Better raindrops are considered as rivers and the remaining raindrops are selected as streams $[20,21,27,28,29]$.

At starting of the algorithm, a matrix of size $\mathrm{N}_{\text {pop }} \mathrm{x}$ $\mathrm{N}_{\mathrm{var}}$ is generated [20,21,28,29]. Hence, a matrix having total population as columns and number of design variables as rows are created [20,21,27,28,29].

Raindrop $=\left[\begin{array}{lll}\mathrm{x}_{1} & \mathrm{x}_{2} \mathrm{x}_{3} \ldots \ldots \mathrm{x}_{\mathrm{Nvar}}\end{array}\right][21]$

Therefore, raindrop population is given by:

Pop $=\left[\begin{array}{c}\text { Raindrop }_{1} \\ \text { Raindrop }_{2} \\ \text { Raindrop }_{3} \\ \vdots \\ \text { Raindrop }_{\mathrm{Npop}}\end{array}\right]$

Cost of the raindrops is given by:

$\operatorname{Cost}_{\mathrm{i}}=\mathrm{f}\left(\mathrm{x}_{1}{ }^{\mathrm{i}}, \quad \mathrm{x}_{2}{ }^{\mathrm{i}}, \quad \mathrm{x}_{3}{ }^{\mathrm{i}} \ldots \mathrm{x}_{\text {Nvar }}{ }^{\mathrm{i}}\right) \quad[21,28,29]$ where $\mathrm{i}=1,2, . . \mathrm{N}_{\text {pop }}$ (26)

The streams are sorted into rivers and sea such that:

$\mathrm{N}_{\mathrm{sr}}=\mathrm{N}_{\mathrm{r}}+1$

$\mathrm{N}_{\text {streams }}=\mathrm{N}_{\text {pop }}-\mathrm{N}_{\mathrm{sr}}$

(28)

Where $\mathrm{N}_{\mathrm{r}}$ represents the number of rivers. "1" represents the best solution i.e. the sea. $\mathrm{N}_{\text {pop }}$ is the total population and $\mathrm{N}_{\text {streams }}$ represents the remaining streams that might directly flow towards the river or sea [28,29].

Based on flow intensity, raindrops are assigned to rivers and sea $[20,27,28,29]$ using the equation shown as:

$\mathrm{NS}_{\mathrm{n}}=$ round $\left\{\mid \frac{\text { Cost }_{\mathrm{n}}}{\sum_{\mathrm{i}=1}^{\mathrm{N}_{\mathrm{s} r}}} \not \times \mathrm{N}_{\text {Raindrops }}\right\}[20,27,28,29]$

Flow of streams towards the river happens through the connecting line using a random distance selected [28] such that:

$\mathrm{X} \in(0, \mathrm{C} \times \mathrm{d}), \mathrm{C}>1[27,28,29]$
Where $C$ is a value that has range between 1 and 2 and its best value will be 2 [27,28,29]. " $d$ " is the present distance between the stream and the river [27,28,29]. Hence, random distances are created initially using the above equation.

The new position for rivers and streams can be given by the equation:

$\mathrm{X}_{\text {stream }}^{\mathrm{i}+1}=\mathrm{X}_{\text {stream }}^{\mathrm{i}}+\operatorname{rand} \times \mathrm{C} \times\left(\mathrm{X}_{\text {River }}^{\mathrm{i}}-\mathrm{X}_{\text {stream }}^{\mathrm{i}}\right)$

(31)

$\mathrm{X}_{\text {stream }}^{\mathrm{i}+1}=\mathrm{X}_{\text {stream }}^{\mathrm{i}}+\operatorname{rand} \times \mathrm{C} \times\left(\mathrm{X}_{\text {sea }}^{\mathrm{i}}-\mathrm{X}_{\text {River }}^{\mathrm{i}}\right)$ (32)

If the solution of the stream is better than that of the river, then the positions of the streams and rivers are exchanged $[21,27,28,29]$. The same condition applies to rivers and sea also. Hence, the search for the best solution is made.

The evaporation condition in the water cycle is the convergence criteria for the algorithm [28]. Hence, the convergence criteria is given by:

$\left|\mathrm{X}_{\text {sea }}^{\mathrm{i}}-\mathrm{X}_{\text {River }}^{\mathrm{i}}\right|<\mathrm{d}_{\max }$ where $\mathrm{i}=1,2,3 \ldots \mathrm{N}_{\mathrm{sr}}-1[28]$

where $d_{\max }$ is a value which is very close to zero. If the distance between river and the sea is less than $d_{\max }$, it represents the joining of rivers to the sea and that describes the evaporation condition $[21,28]$.

With the increase in the number of iterations, the value of $d_{\max }$ decreases [20,21,28,29] as shown by the equation:

$\mathrm{d}_{\max }^{\mathrm{i}-1}=\mathrm{d}_{\max }^{\mathrm{i}}-\left(\mathrm{d}_{\max }^{\mathrm{i}-1} / \max\right.$ iteration $)$

After the evaporation process is satisfied, the water cycle again starts and new raindrops have to be created. Those raindrops form streams which flow in different locations [28]. The new locations of the streams are given by:

$\mathrm{X}_{\text {stream }}^{\text {new }}=\mathrm{LB}+\operatorname{rand} \times(\mathrm{UB}-\mathrm{LB})[28]$

Hence, the $2^{\text {nd }}$ iteration starts with the formation of new raindrops and the water cycle process repeats.

\section{GRAPHICAL ANALYSIS OF THE PROPOSED DRIVE}

MATLAB-SIMULINK environment is utilized in simulating the BLDC drive. Air- conditioner compressor is considered as the load having a load torque of $1.1 \mathrm{Nm}$. The rated values of power and speed are considered as $375 \mathrm{~W}$ and 3000rpm respectively. Regulation of the motor speed is done by tracking the DC reference which is equivalent to the motor speed. 
Fig.3 shows the input parameters before doing the enhancement of power quality. It can be seen that the amplitude of the input current is very high and hence it can result in equipments connected to it getting damaged.

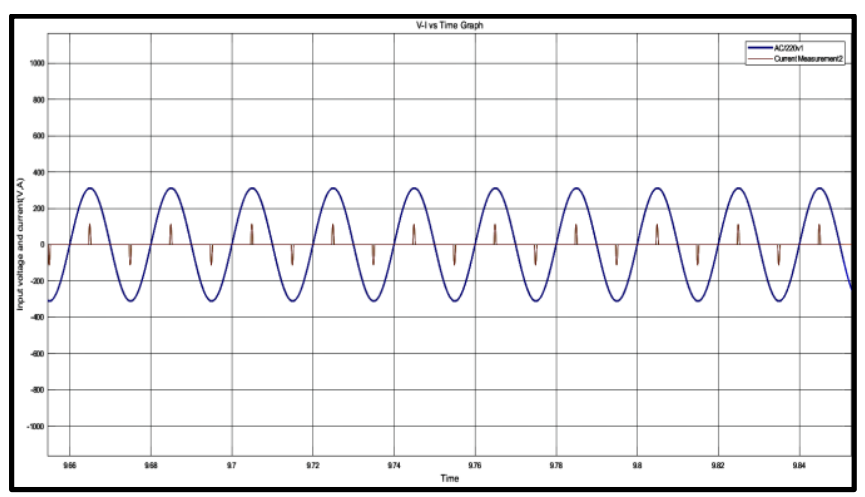

Fig 3:- Input parameters before power quality enhancement

Fig. 4 shows the total block diagram in Simulink which describes the whole system used in improving the power quality. The input block has step down transformer and bridge rectifier which gives pulsating DC voltage. The interleaved converter block has the converter which increases the voltage to the desired level. The converter excites the inverter which is used to power the BLDC motor. The rotor position is fed back and is given to the decoder block. The decoder block converts the Hall sensor signals to a unity amplitude quasi rectangular wave. These signals are given to the Gates block where the signals are fed to the inverter depending upon the output of the decoder block.

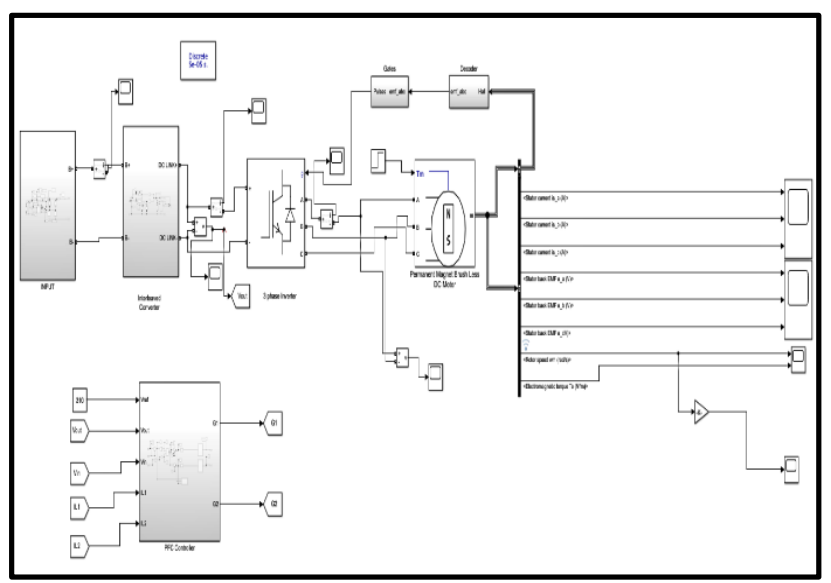

Fig 4:- Block diagram in Simulink showing the whole system for power factor enhancement

Fig. 5 shows the main controller block for the system. It consists of a slowly acting outer speed controller and two quickly acting inner current controllers. The signals from the current controllers are given to a PWM generator which provides the gating signals to MOSFETs of the converter.

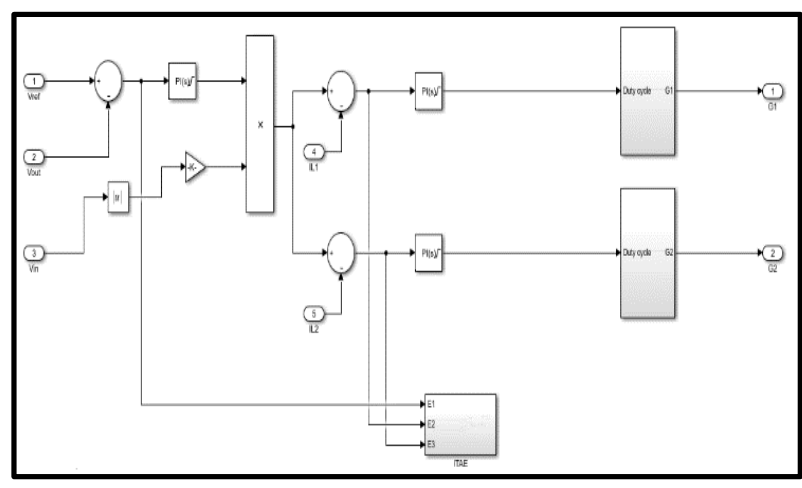

Fig 5:- Controller block for the PFC system

Fig. 6 displays the ITAE block which consists of the summation block which adds all the absolute value of errors and integrates with time and the final value is given to the MATLAB workspace.

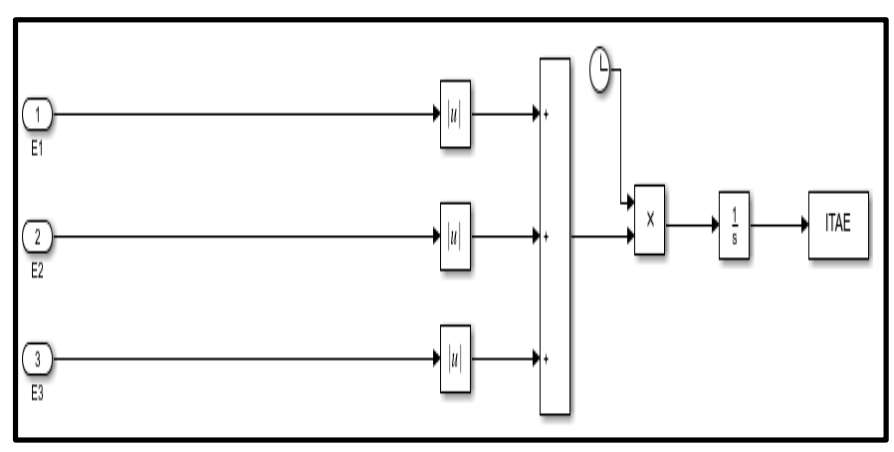

Fig 6:- ITAE block

The simulation in MATLAB Simulink is done for a converter output voltage of $310 \mathrm{~V}$ and current of $1.62 \mathrm{~A}$. A constant compressor load torque of $1.1 \mathrm{Nm}$ is maintained.

Fig. 7 shows the stator EMF for all three phases.

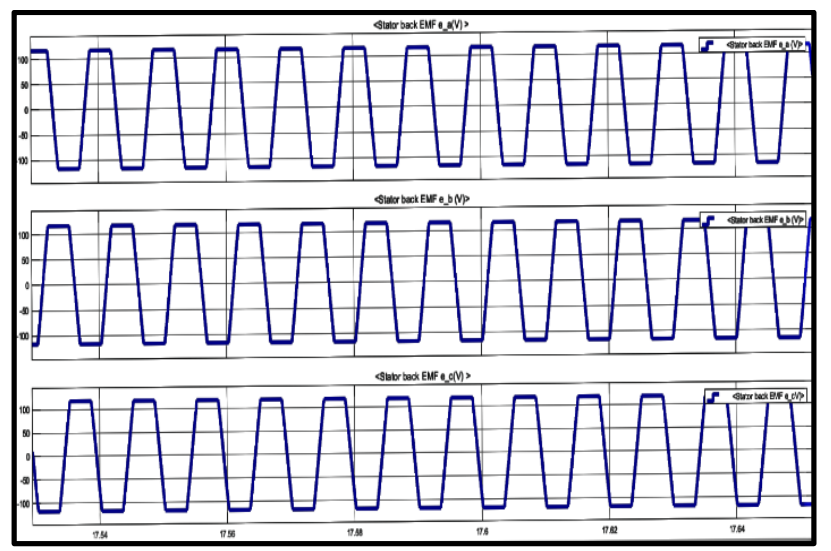

Fig 7:- Stator EMF for all three phases

The EMFs are having $120^{\circ}$ phase difference and are trapezoidal in shape as expected. EMF produced by the motor varies corresponding to the variation in the speed of the motor. 
ISSN No:-2456-2165

Fig. 8 shows the input current i.e. stator current of all three phases.

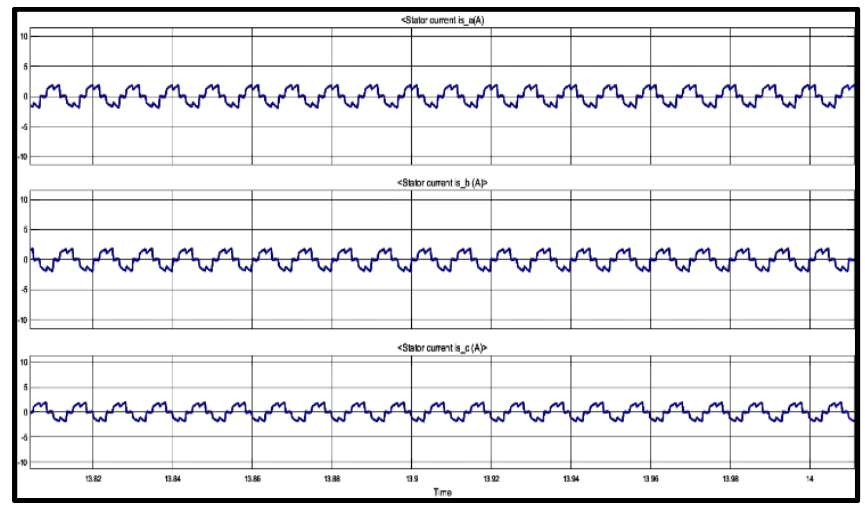

Fig 8:- Stator current

The stator windings of the BLDC motor are excited by the inverter with quasi-rectangular currents on all three phases with $120^{\circ}$ phase shift. The instantaneous power at any movement is given by:

$P_{\text {inst }}=2 * E_{x} * I_{x}$

Where $E_{x}$ and $I_{x}$ represent the instantaneous EMF and current value. " $\mathrm{x}$ " represents the three phases.

Fig. 9 shows the speed-torque graphs for the rated values.

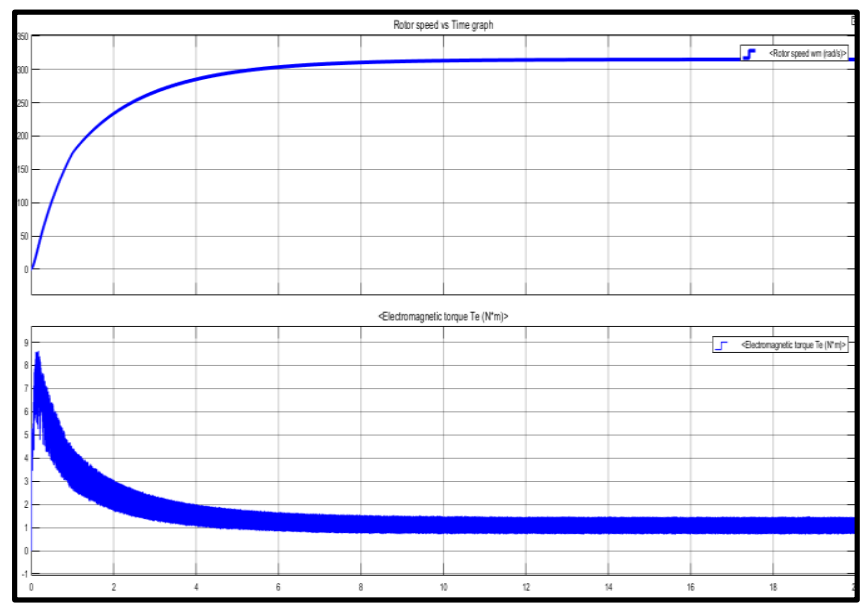

Fig 9:- Speed and Torque Graph

Since the load torque is kept constant, the electromagnetic torque remains constant for different speeds. Speed regulation is done by operating the motor at different power levels.

Fig. 10 shows how the reference voltage $\mathrm{V}_{\mathrm{DC}}$ is tracked by the converter output voltage using the controller-

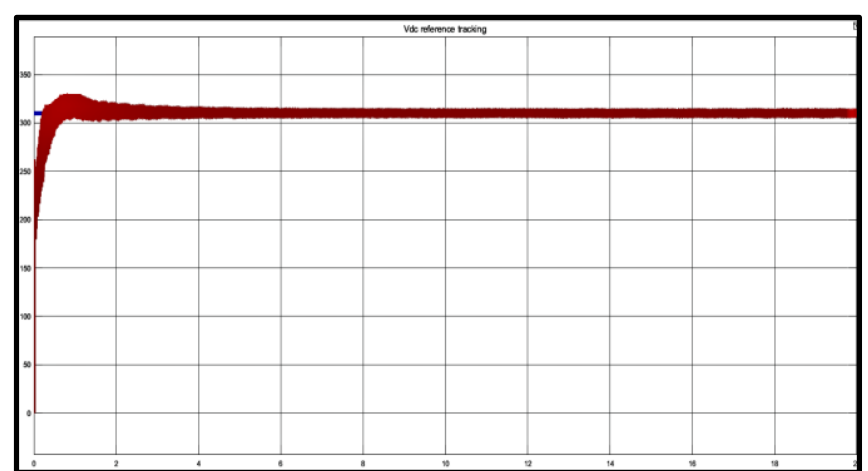

Fig 10:- Voltage Reference tracking

The main aim of the controller is to make sure that the converter output voltage follows the reference voltage. The parameters of the controller should be thereby adjusted to obtain the desired speed.

The system is modelled in SIMULINK environment and the code for the WCA and objective function are written in MATLAB platform. The objective function is estimated using the algorithm and the PI controller parameters are tuned optimally.

Table 4 shows the comparison between the manual PI tuning and that which is done using water cycle algorithm.

\begin{tabular}{|c|c|c|}
\hline Parameters & $\begin{array}{c}\text { Manual } \\
\text { Tuning }\end{array}$ & $\begin{array}{c}\text { Tuning using } \\
\text { algorithm }\end{array}$ \\
\hline $\mathrm{K}_{\mathrm{P} 1}$ & 0.2 & 0.9997 \\
\hline $\mathrm{K}_{\mathrm{I} 1}$ & 0.04 & 0.1683 \\
\hline $\mathrm{K}_{\mathrm{P} 2}$ & 0.9 & 0 \\
\hline $\mathrm{K}_{\mathrm{I} 2}$ & 0.8 & 1 \\
\hline $\mathrm{K}_{\mathrm{P} 3}$ & 0.9 & 0.9999 \\
\hline $\mathrm{K}_{\mathrm{I} 3}$ & 0.8 & 1 \\
\hline
\end{tabular}

Table 4:- Comparison between manual tuning and tuning using algorithm

It can be observed from the table, that the gains obtained using the algorithm is more precise than that done manually. Therefore, it results in a better power factor.

Fig. 11 shows the graph of the variation of values of Fitness function ITAE w.r.t. the number of iterations.

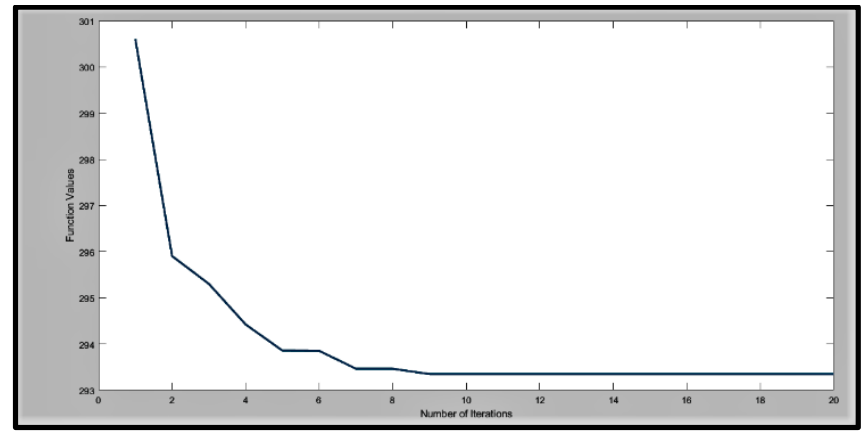

Fig 11:- Fitness function variation with number of iterations 
The total population and number of iterations are chosen as 50 and 20 respectively. The lower bound for the PI parameters is considered as 0 and upper bound for speed PI is 4 and current PI is 1 respectively. It can be observed that the best fitness function value converges to 293.3498 after the $9^{\text {th }}$ iteration. Hence, more the number of iterations, more is the chance of getting the best solution.

Fig. 12 displays the THD of the input current for different harmonic orders. The THD is expected to meet the international standards of PQ IEC 61000-3-2 [13,30].

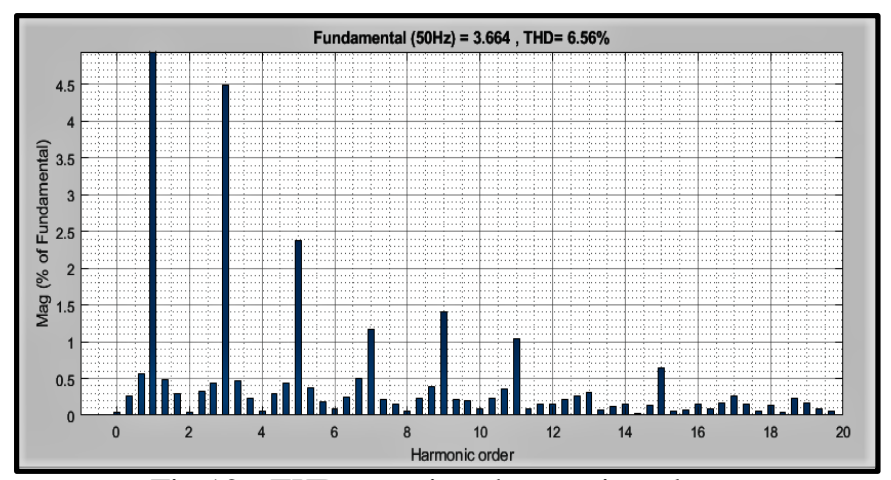

Fig 12:- THD at various harmonic orders
Fig. 13 displays the Input parameters after Power quality enhancement.

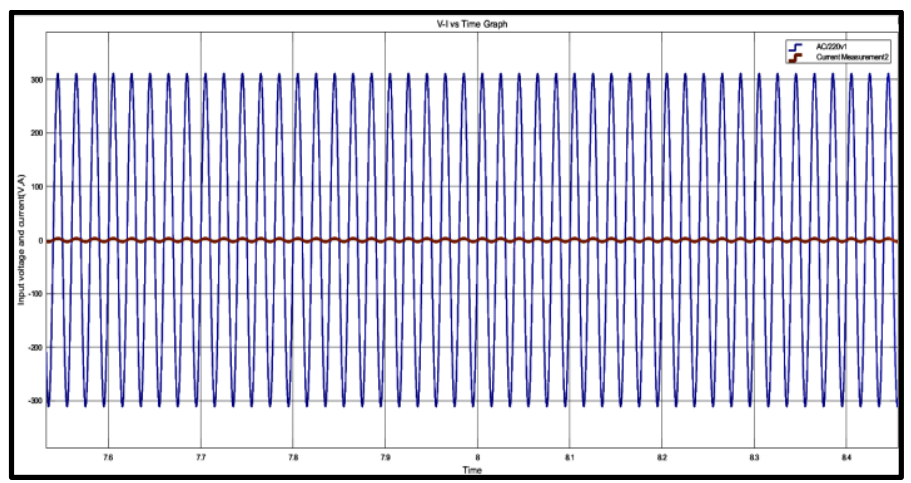

Fig 13:- Input parameters after power quality enhancement

The input current is as desired for the power factor improvement i.e. it is in phase with the input voltage which makes the power factor near to unity.

Table 5 represents the main aim of enhancement of power quality and speed regulation. It is observed that a power factor of more than 0.99 is maintained for different speed levels.

\begin{tabular}{|c|c|c|c|c|}
\hline $\mathrm{V}_{\mathrm{DC}}$ & Speed(rpm) & EMF(V) & THD & PF \\
\hline 310 & 3000 & 117 & $6.56 \%$ & 0.9982 \\
\hline 295 & 2828 & 110 & $8.23 \%$ & 0.9961 \\
\hline 280 & 2670 & 104 & $8.51 \%$ & 0.9958 \\
\hline 265 & 2500 & 97 & $8.50 \%$ & 0.9949 \\
\hline 250 & 2330 & 90 & $8.59 \%$ & 0.9937 \\
\hline 235 & 2162 & 84 & $8.79 \%$ & 0.9925 \\
\hline 220 & 2000 & 77 & $8.86 \%$ & 0.9917 \\
\hline 205 & 1822 & 70 & $9.13 \%$ & 0.9912 \\
\hline 190 & 1652 & 57 & $9.67 \%$ & 0.9907 \\
\hline 175 & 1481 & 25 & $10.46 \%$ & 0.9901 \\
\hline
\end{tabular}

Table 5:- Power Factor at mains supply for different motor speeds

VIII. CONCLUSIONS

The design and simulation analysis of the BLDC drive is carried out in MATLAB Simulink software. The PI controllers tuned by water cycle algorithm using ITAE criterion has proved to be an efficient tuning method. Power factor is nearer to unity at different speed levels. Also the speed regulation obtained for the Air-conditioner compressor load is satisfactory. The drive circuit has shown improvement in power quality at $\mathrm{AC}$ mains for different speeds. The PQ parameters obtained are acceptable according to International standards IEC 61000-3-2. Speed regulation for the Air-conditioner compressor load is also achieved by regulating the converter output voltage to different levels. The presented drive has caused enhanced power quality for different speeds. The PQ parameters obtained are in same range with the standard values. Since, the results are satisfactory, this drive proves to be very much suitable for Air-conditioning application.

\section{ACKNOWLEDGEMENT}

Authors are grateful to the Management, BMS Educational Trust, Principal and Vice-Principal, BMS College of Engineering.

\section{REFERENCES}

[1]. Tony Mathew, Caroline Ann Sam, "Modeling and Closed Loop Control of BLDC Motor using a Single Current Sensor", in International Journal of Advanced Research in Electrical, Electronics and Instrumentation Engineering Vol. 2, Issue 6, June 2013, pp. - 2525-2531

[2]. Arunkumar, Thangavel "A Review Paper on Torque Ripple Reduction and Power Quality Improvement in Brushless DC Motor Drives", in International Electrical Engineering Journal (IEEJ) Vol. 5 (2014) No.10, pp. 1567-1575. 
[3]. V N Arjun, H Akhilesh Nair, G Balakrishnan, T S Vishnu, Vidya Sojan, "Speed Control of a BLDC Motor Using PWM Control Technique", in International Journal of Innovative Research in Electrical, Electronics, Instrumentation and Control Engineering Vol. 4, Issue 6, June 2016, pp. 18-21.

[4]. S Ragu, "Simulation of Speed Control of Brushless DC Motor for four Quadrant Operation", in International Journal for Research in Applied Science \& Engineering Technology (IJRASET) Volume 2 Issue XII, December 2014.

[5]. M. Poovizhi, M. Senthil Kumaran, P. Ragul, L. Irene Priyadarshini, R. Logambal. "Investigation of mathematical modelling of brushless $\mathrm{dc}$ motor (BLDC) drives by using matlab-simulink", in 2017 International Conference on Power and Embedded Drive Control (ICPEDC).

[6]. Bikram Das, Mahua Chanda, "Torque Ripple Reduction and Speed Performance of BLDCM Drive with Hysteresis Current Controller", in International Journal of Engineering Research \& Technology, (pp 194-201).

[7]. Sachin Saini, Dheeraj Kumar Dhaked, Piyush Sharma. "A Comprehensive Review of Different Control Techniques For The permanent Magnet Brushless Dc Motor Drives", in International Journal for Technological Research in Engineering, February 2018.

[8]. Shivani Mishra, S.S.Thakur, S.P.Phulambrikar, "Speed Control of PMBLDC Motor with the Help of PI Controller", in SSRG International Journal of Electrical and Electronics Engineering (SSRG-IJEEE) volume 2 Issue 10 October2015.

[9]. S. Athiyaman, K. Prakasam, "Power Quality Improvement In PMBLDCM Drive Using PFC Sepic Converter For Air Conditioner", in International Journal of Engineering Sciences \& Research Technology, (pp. 1668-1674).

[10]. Sanjeev Singh, Bhim Singh "A Voltage-Controlled PFC Cuk Converter-Based PMBLDCM Drive for AirConditioners", in IEEE Transactions on Industry Applications, Vol. 48, NO. 2, March/April 2012, (pp. 832-838).

[11]. Vashist Bist, Bhim Singh, “An Adjustable-Speed PFC Bridgeless Buck-Boost Converter-Fed BLDC Motor Drive", in IEEE Transactions n Industrial Electronics, VOL. 61, NO. 6, June 2014, pp. 2265-2677.

[12]. Vashist Bist, Bhim Singh, "A PFC Based BLDC Motor Drive Using a Canonical Switching Cell (CSC) Converter", in IEEE Transactions On Industrial Electronics January 2014.

[13]. Limits for Harmonic Current Emissions (Equipment Input Current $\leq 16$ A per Phase), Int. Std. IEC 61000-32, 2000.

[14]. C. Subba rami Reddy ,S.P. Sathyavathi, "Power Factor Correction of BLDC Motor Drive Using Bridge Less Buck-Boost Converter", in International Journal of Science, Engineering and Technology Research (IJSETR), Volume 4, Issue 2, February 2015, pp. 372-381.
[15]. Srinu Duvvada, B. Manmadha Kumar, "A Single Phase to Three Phase PFC Half-Bridge Converter Using BLDC Drive with SPWM Technique", in Srinu Duvvada Int. Journal of Engineering Research and Applications ISSN: 2248-9622, Vol. 4, Issue 7(Version 3), July 2014, pp. 31-38.

[16]. Stephy Mathew, J. Nayana, "Review of DC-DC Converters for PFC in SMPS", in IOSR Journal of Electrical and Electronics Engineering (2017), pp. 3543.

[17]. Sonu Jayachandran, Pavana and Vinatha U, "One Cycle Controlled Bridge-less SEPIC Converter Fed BLDC Motor Drive", 978-1-5386-3864-4/17/\$31.00, 2017 IEEE (2017).

[18]. V. Aishwarya, C. Kavitha, R. Kaviya, R. Seyezhai, "Investigation of Boost and Interleaved Boost Switched Mode Rectifiers for Power Factor Correction", in International Journal of Industrial Electronics and Electrical Engineering, ISSN: $2347-$ 6982 Volume-4, Issue-11, Nov.-2016, pp. 24-30.

[19]. E.H.E. Bayoumi, H.M. Soliman, "PID/PI tuning for Minimal Overshoot of PM Brushless DC Motor Drive Using Swarm Optimization"(2007), pp. 198-208.

[20]. Mohamed Barakat, Ahmed Donkol, Hossam Al Rahall, "Water Cycle Algorithm Optimized for a Centralized PID controller for Frequency Stability of a Real Hybrid Power System", in 2019 21st International Middle East Power Systems Conference (MEPCON), Tanta University, Egypt, pp. 1112-1118.

[21]. Tarek Hassan Mohamed, Hussein Abubakr, Mohamed Abdelhamid Mohamed Alamin, Ammar Mostafa Hassan, "Modified WCA-Based Adaptive Control Approach Using Balloon Effect: Electrical Systems Applications", in March 2020, pp. 60877-60889.

[22]. G. Fernando Martins, "Tuning the PID controllers using ITAE criterion", in May 2005.

[23]. Bhim Singh, Vashist Bist, "A BL-CSC Converter Fed BLDC Motor Drive with Power Factor Correction", in IEEE Transactions on Industrial Electronics (2014).

[24]. S. Shreekara Hegde, A.N.Nagashree, "Improvement of Power Quality and Speed Regulation of A BLDC Motor Drive Using an Interleaved Converter", in International Journal of Engineering Applied Sciences and Technology, 2020 Vol. 5, Issue 2, ISSN No. 2455-2143, pp. 149-155.

[25]. U. Vinatha, , Swetha Pola, Dr K.P.Vittal, " Simulation of Four Quadrant Operation \& Speed Control of BLDC Motor on MATLAB / SIMULINK".

[26]. Deepyaman Maiti, Ayan Acharya, Mithun Chakraborty, Amit Konar, Ramadoss Janarthanan, "Tuning PID and PID Controllers using the Integral Time Absolute Error Criterion", 978-1-4244-29004/08/\$25.00 @2008 IEEE.

[27]. M.A. Elhameed, A.A. El-Fergany "Water Cycle Algorithm-based Load Frequency Controller for Interconnected Power Systems Comprising Nonlinearity", in IET Generation, Transmission \& Distribution. 
[28]. Hadi Eskandar, Ali Sadollah, Ardeshir Bahreininejad, Mohd Hamdi, "Water cycle algorithm - A novel metaheuristic optimization method for solving constrained engineering optimization problems", 2012 Elsevier Ltd, pp. 151-166.

[29]. Kong Yanjun, Mei Yadong, Li Weinan, Wang Xianxun, Ben Yue, "An Enhanced Water Cycle Algorithm for Optimization of Multi-Reservoir systems", 978-1-5090-5507-4/17/\$31.00 (C2017 IEEE ICIS 2017, May 2017.

[30]. Sanjeev Singh, Bhim Singh, "PFC Bridge Converter for Voltage-controlled Adjustable-speed PMBLDCM Drive", in Journal of Electrical Engineering \& Technology Vol. 6, No. 2, November 2010 pp. 215225. 